\title{
Genetic and environmental variance and covariance parameters for some reproductive traits of Holstein and Jersey cattle in Antioquia (Colombia)
}

\author{
Juan Carlos Zambrano ${ }^{1}$, Julián Echeverri² \\ 1 Universidad Nacional de Colombia Sede Medellin, Facultad de Ciencias, Posgrado en Biotecnología, Medellín, Colombia. \\ 2 Universidad Nacional de Colombia Sede Medellín, Facultad de Ciencias Agropecuarias, Departamento de Producción Animal, Medellín \\ Colombia.
}

ABSTRACT - The objective of this study was to estimate the genetic, phenotypic and environmental parameters for calving interval (CI), days open (DO), number of services per conception (NSC) and conception rate (CR) in Holstein and Jersey cattle in Antioquia (Colombia). Variance and covariance component estimates were obtained by an animal model that was solved using the derivative-free restricted maximum likelihood method. The means and standard deviations for CI, DO, NSC and CR were: $430.32 \pm 77.93$ days, $127.15 \pm 76.96$ days, $1.58 \pm 1.03$ services per conception and $79.88 \pm 28.66 \%$ in Holstein cattle, and $409.33 \pm 86.48$ days, $125.62 \pm 86.09$ days, $1.48 \pm 0.98$ services per conception and $84.08 \pm 27.23 \%$ in Jersey cattle, respectively. The heritability estimates (standard errors) were: $0.088(0.037), 0.082(0.037), 0.040(0.025)$ and $0.030(0.026)$ in Holstein cattle and 0.072(0.098), 0.090(0.104), 0.093(0.097) and 0.147(0.117) in Jersey cattle, respectively. The results show that the genetic, phenotypic and permanent environmental correlations in the two evaluated breeds were favorable for CI $\times$ DO, $\mathrm{CI} \times \mathrm{NSC}$ and $\mathrm{DO} \times \mathrm{NSC}$, but not for $\mathrm{CI} \times \mathrm{CR}, \mathrm{DO} \times \mathrm{CR}$ and $\mathrm{NSC} \times \mathrm{CR}$. Genetic and permanent environmental correlations were high in most cases in Holstein cattle, whereas in Jersey cattle they were moderate. In contrast, phenotypic correlations were very low in both breeds, except for CI $\times$ DO and NSC $\times \mathrm{CR}$, which were high. Overall, the genetic component found was very low $(\leq 8 \%)$ in both evaluated breeds and this implies that their selection would take long time and that a good practical management of the herd will be essential in order to improve the reproductive performance.

Key Words: fertility, genetic correlation, heritability, repeatability

\section{Introduction}

Fertility traits are considered very important because of their impact on the economy of dairy cattle breeding. Economic losses due to fertility problems are mainly caused by low dairy yield, prolonged calving intervals, increased insemination costs, few calves per cow per year, increased culling, high replacement costs and shorter reproductive lifespans (Abe et al., 2009; González-Recio and Alenda, 2005). Nonetheless, for many years, genetic improvement programs worldwide did not include reproductive performance, since the selection was mainly focused on milk yield. An exception was Scandinavia, whose selection indices included not only milk yield, but also health and reproductive traits (Miglior et al., 2005). Now, the increase in milk yield without considering the reproductive performance is a problem, because it produced an important decline in the reproductive efficiency over time (Pryce et al., 2004; Melendez and Pinedo, 2007).

It is difficult to determine which traits must be included in the genetic evaluation of fertility, since they have very low heritability values, i.e., close to 0.1 (Thaller, 1997;
Jamrozik et al., 2005). However, over the last decade, reproductive traits have increasingly been included in the selection indices for reproductive traits in genetic evaluations in different countries, thus highlighting the importance of including fertility in improvement programs of dairy cattle (Miglior et al., 2005). Nevertheless, genetic improvement of reproductive traits is almost non-existent in Colombia. Even though some improvement programs for increasing dairy yield have been implemented, they have not survived due to the lack of financial resources. As a consequence, there is currently a lack of information on all the genetic components involved, and specifically on reproductive variables such as calving interval, age at first service, age at first calving, and days open, among others (García et al., 2002; Grajales et al., 2006). The existing literature is therefore rather limited. Further research on how to increase dairy yield, reproduction and health of dairy cattle is required.

The objective of this study was to estimate the genetic, phenotypic and environmental parameters for calving interval (CI), days open (DO), number of services per conception (NSC) and conception rate (CR) in Holstein and Jersey cattle in Antioquia (Colombia). 


\section{Material and Methods}

This research was approved by the Ethics Committee of Universidad Nacional de Colombia sede Medellín, considering that it meets the standards for this type of research (Approval letter number: CEMED-015 May 2012).

The data for this study was obtained from 88 Holstein and Jersey dairy herds in 18 municipalities of Antioquia (Colombia). Specific health and feeding management conditions were different for each dairy farm, as well as topography and geographical location.

All herd information regarding breeding or health - calving dates, dry dates, pregnancy detection dates, insemination dates, cow entry/exit, etc - was obtained from historical records, notebooks and cattle management software. This information was entered, analyzed and saved using the Control 1 Software, version 1.0 of the Animal Genetic Improvement Laboratory at Universidad Nacional de Colombia sede Medellín. Data selection was based upon reliability: information whose validity could not be guaranteed was deleted from the final data set before analysis, as were extreme values that were considered physiologically abnormal or erroneously coded.

The reproductive traits evaluated in this study were: calving interval (CI), measured as the number of days between two consecutive calving; days open (DO), measured as the days between calving and conception; number of services per conception (NSC), defined as the number of inseminations until pregnancy; and conception rate (CR), defined as the percentage of successful inseminations $[\mathrm{CR}=(1 / \mathrm{NSC}) * 100]$. The number of Holstein animals was 7,937, of which 275 were bulls. For Jersey cattle, there were a total of 833 animals, including 56 bulls.

To (co) variance components were estimated by Derivativefree Restricted Maximum Likelihood Method using the MTDFREML software (Boldman et al., 1995), which estimates fixed and random effect solutions by solving the mixed models equations (MME), described by Henderson (1984).

Variance components for CI, DO, NSC and CR were estimated through univariate analysis using an animal model considering the effects of herd, number of calving and contemporary group as fixed, and the permanent environmental, animal additive genetic and residual effects as random. The contemporary group included municipality, year of calving and calving season. The model used (Mrode, 1996) can be described as:

$$
y=X b+W p e+Z a+e
$$

in which $y=$ vector of observations; $b=$ vector of fixed effects (herd, number of calving, and contemporary group); $p e=$ vector of random permanent environmental effects; $a=$ vector of random animal effects; $e=$ vector of random residual effects; $X, W$, and $Z=$ incidence matrices that establish relationships between the records and the effects.

It is assumed that permanent environmental, animal, and residual effects are independently distributed with mean zero and variance:

$$
V\left[\begin{array}{c}
a \\
p e \\
e
\end{array}\right]=\left[\begin{array}{ccc}
A \sigma_{a}^{2} & 0 & 0 \\
0 & I \sigma_{p e}^{2} & 0 \\
0 & 0 & I \sigma_{e}^{2}
\end{array}\right]
$$

Considering that $A=$ relationship matrix, $I \sigma_{e}^{2}=R$, then $V(y)=Z A Z^{\prime} \sigma_{a}^{2}+W I \sigma_{p e}^{2} W^{\prime}+R$. Thus, the mixed model equations for the best linear unbiased estimator (BLUE) of estimable functions of $b$ and for the best linear unbiased prediction (BLUP) of $p e$ and $a$ are:

$$
\left[\begin{array}{c}
b \\
a \\
p e
\end{array}\right]=\left[\begin{array}{ccc}
X^{\prime} X & X^{\prime} Z & X^{\prime} W \\
Z^{\prime} X & Z^{\prime} Z+A_{\alpha 1}^{-1} & Z^{\prime} W \\
W^{\prime} X & W^{\prime} Z & W^{\prime} W+I_{\alpha 2}
\end{array}\right]^{-1}=\left[\begin{array}{c}
X^{\prime} y \\
Z^{\prime} y \\
W^{\prime} y
\end{array}\right]
$$

in which $A=$ relationship matrix; and $a_{1}=\sigma^{2}{ }_{e} / \sigma^{2}{ }_{a}$ and $a_{2}=\sigma_{e}^{2} / \sigma_{p e}^{2}$.

Heritability was estimated as the ratio of the additive genetic variance to total phenotypic variance; and repeatability, as the ratio of the sum of the additive genetic variance plus permanent environmental variance to phenotypic variance, as described by Falconer and Mackay (2001):

$$
\begin{gathered}
h^{2}=\sigma_{a}^{2} /\left(\sigma_{a}^{2}+\sigma_{p e}^{2}+\sigma_{e}^{2}\right) ; \\
R=\left(\sigma_{a}^{2}+\sigma_{p e}^{2}\right) /\left(\sigma_{a}^{2}+\sigma_{p e}^{2}+\sigma_{e}^{2}\right) .
\end{gathered}
$$

To estimate genetic, phenotypic, residual and permanent environmental correlations, a bivariate model was used including herd, number of calving and contemporary group (which included municipality, year of calving and calving season) as the fixed effects, and the permanent environmental and additive genetic direct effects as random. The matrix model used was:

$\left[\begin{array}{l}y_{1} \\ y_{2}\end{array}\right]=\left[\begin{array}{cc}X_{1} & 0 \\ 0 & X_{2}\end{array}\right]\left[\begin{array}{l}b_{1} \\ b_{2}\end{array}\right]+\left[\begin{array}{cc}Z_{1} & 0 \\ 0 & Z_{2}\end{array}\right]\left[\begin{array}{l}a_{1} \\ a_{2}\end{array}\right]+\left[\begin{array}{cc}W_{1} & 0 \\ 0 & W_{2}\end{array}\right]\left[\begin{array}{l}p e_{1} \\ p e_{2}\end{array}\right]+\left[\begin{array}{l}e_{1} \\ e_{2}\end{array}\right]$

in which $y_{i}=$ vector of $\mathrm{N}$ observations; $b_{i}=$ vector of fixed effects (herd, number of calving, contemporary group); $p e_{i}=$ vector of random permanent environmental effects; $a_{i}=$ vector of random animal effects; $e_{i}=$ vector of random residual effects; $X, W$, and $Z=$ incidence matrices establishing relationships between the records and the fixed and random effects, respectively.

It is assumed that random permanent environmental, animal and error effects are independently distributed with mean of zero and variance: 


$$
\begin{gathered}
V\left[\begin{array}{c}
a \\
p e \\
e
\end{array}\right]=\left[\begin{array}{ccc}
G_{0} \otimes A & 0 & 0 \\
0 & Q_{0} \otimes I & 0 \\
0 & 0 & R_{0} \otimes I
\end{array}\right] \\
G_{0}=\left[\begin{array}{ll}
\sigma_{a i i}^{2} & \sigma_{a i j} \\
\sigma_{a j i} & \sigma_{a j j}^{2}
\end{array}\right], Q_{0}=\left[\begin{array}{cc}
\sigma_{p e i i}^{2} & \sigma_{p e i j} \\
\sigma_{p e j i} & \sigma_{p e j j}^{2}
\end{array}\right], R_{0}=\left[\begin{array}{ll}
\sigma_{e i i}^{2} & \sigma_{e i j} \\
\sigma_{e j i} & \sigma_{e j j}^{2}
\end{array}\right]
\end{gathered}
$$

in which $\otimes=$ direct or Kronecker product; $I=$ identity matrix equal to number of observations; $A=$ relationship matrix among all animals in the pedigree; $G_{0}=$ variance and covariance matrix of random animal effects; $\sigma_{\text {aii }}^{2}=$ animal additive genetic variance for trait $i ; \sigma_{a j i}^{2}=$ animal additive genetic variance for trait $j ; \sigma_{a i j}=\sigma_{a j i}=$ animal additive genetic covariance between traits $i$ and $j ; Q_{0}=$ variance and covariance matrix of random permanent environmental effects; $\sigma_{\text {peii }}^{2}=$ permanent environmental variance for trait $i$; $\sigma_{p e j j}^{2}=$ permanent environmental variance for trait $j ; \sigma_{p e i j}=$ $\sigma_{p e j i}=$ permanent environmental covariance between traits $i$ and $j ; R_{0}=$ variance and covariance matrix of residual effects; $\sigma_{e i i}^{2}=$ residual variance for trait $i ; \sigma_{e j j}^{2}=$ residual variance for trait $j$; and $\sigma_{e i j}=\sigma_{e j i}=$ residual covariance between traits $i$ and $j$.

The mixed model equations for the best linear unbiased estimator (BLUE) of estimable functions of $b$ and for the best linear unbiased prediction (BLUP) of $a$ and $a p$ are:

$\left[\begin{array}{c}\hat{b} \\ \hat{a} \\ \hat{p} e\end{array}\right]=\left[\begin{array}{ccc}X^{\prime} R^{-1} X & X^{\prime} R^{-1} Z & X^{\prime} R^{-1} W \\ Z^{\prime} R^{-1} X & Z^{\prime} R^{-1} Z+k_{1} & Z^{\prime} R^{-1} W \\ W^{\prime} R^{-1} X & W^{\prime} R^{-1} Z & W^{\prime} R^{-1} W+I^{*} Q^{-1}\end{array}\right]^{-1}=\left[\begin{array}{c}X^{\prime} R^{-1} y \\ Z^{\prime} R^{-1} y \\ W^{\prime} R^{-1} y\end{array}\right]$ in which $k_{1}=G_{0} * A^{-1}, \hat{b}=\left[\begin{array}{l}\hat{b}_{1} \\ \hat{b}_{2}\end{array}\right], \hat{a}=\left[\begin{array}{l}\hat{a}_{1} \\ \hat{a}_{2}\end{array}\right]$ and $\hat{p} e=\left[\begin{array}{l}\hat{p} e_{1} \\ \hat{p} e_{2}\end{array}\right]$.

The estimates of genetic $\left(\mathrm{r}_{\mathrm{g}}\right)$, permanent environmental $\left(\mathrm{r}_{\mathrm{pe}}\right)$, residual $\left(\mathrm{r}_{\mathrm{e}}\right)$, and phenotypic $\left(\mathrm{r}_{\mathrm{p}}\right)$ correlations were obtained from the estimation of covariance components using the following equations:

$r_{g}=\frac{\sigma_{a i j}}{\sqrt{\sigma_{a i i}^{2} \sigma_{a j j}^{2}}}, r_{p e}=\frac{\sigma_{p e i j}}{\sqrt{\sigma_{p e i i}^{2} \sigma_{p e j j}^{2}}}, r_{e}=\frac{\sigma_{e i j}}{\sqrt{\sigma_{e i i}^{2} \sigma_{e j j}^{2}}}, r_{p}=\frac{\sigma_{p i j}}{\sqrt{\sigma_{p i i}^{2} \sigma_{p j j}^{2}}}$

in which $\sigma_{p i j}=$ phenotypic covariance between traits $i$ and $j$; $\sigma_{p i i}^{2}=$ phenotypic variance for trait $i$; and $\sigma_{p j j}^{2}=$ phenotypic variance for trait $j$.

\section{Results}

Regarding the statistical summary for the four evaluated traits CI (days), DO (days), NSC and CR (\%) in the Holstein and Jersey breeds (Table 1), the means for Holstein cattle were: $410.32 \pm 77.93$ days, $127.5 \pm 76.96$ days, $1.58 \pm 1.03$ and $79.88 \pm 28.66 \%$, respectively. Very similar results were obtained for Jersey cattle: $409.33 \pm 86.48$ days,
$125.62 \pm 86.09$ days, $1.48 \pm 0.98$ and $84.08 \pm 27.23 \%$. The traits with the highest variability for both breeds according to the variation coefficient were DO and NSC (Holstein: $60.53,65.07 \%$ and Jersey: $68.53,66.00 \%$ ) and those with the lowest variation, CI and CR (Holstein: 18.99, 35.88\% and Jersey: 21.13, 32.38\%).

The heritability and repeatability estimates for Holstein and Jersey cattle (Table 2) were lower than 0.15, and the heritability estimates for CI, DO, NSC and CR were $0.088 \pm 0.037,0.082 \pm 0.037,0.040 \pm 0.025$ and $0.030 \pm 0.026$ for the Holstein and $0.072 \pm 0.098,0.090 \pm 0.104,0.093 \pm 0.097$ and $0.147 \pm 0.117$ for the Jersey breeds, respectively. The heritability values for CI and DO were similar for the two breeds, but higher for NSC and CR in Jersey cattle.

The repeatability estimates for CI, DO, NSC and CR were $0.093 \pm 0.037,0.101 \pm 0.037,0.069 \pm 0.026$ and $0.076 \pm 0.027$ for Holstein cattle, and $0.074 \pm 0.116$, $0.091 \pm 0.123,0.094 \pm 0.105$ and $0.147 \pm 0.121$ for Jersey cattle. The repeatability values were similar for the two breeds for CI, DO and NSC, but they were higher for CR of Jersey cattle.

Permanent environmental variance was lower than genetic variance in both breeds in all cases (Table 3). Permanent environmental variance was higher for Holstein than Jersey cattle, since the number of studied lactations was lower in the latter. It should be noted that all the variances change for one trait depending on the trait with which it is correlated, because the number of observations of the two correlated traits must be balanced to calculate the standard errors of their genetic parameters.

According to the results obtained in this study, genetic, permanent environmental and phenotypic correlations can be classified into two groups for both breeds: group 1, or positive correlations: $\mathrm{CI} \times \mathrm{DO}, \mathrm{CI} \times \mathrm{NSC}$ and $\mathrm{DO} \times \mathrm{NSC}$, and group 2, or negative correlations: $\mathrm{CI} \times \mathrm{CR}, \mathrm{DO} \times \mathrm{CR}$ and NSC $\times$ CR (Table 4). Genetic correlations were high in both groups (group 1: 0.980, 0.955 and 0.988; group 2: $-1.00,-0.993$ and -1.00$)$ for Holstein cattle, respectively, whereas for Jersey cattle they were high in some cases and moderate in others (group 1: 1.00, 0.541 and 0.490; group 2: $-0.250,-0.250$ and -0.890$)$, respectively. Permanent environmental correlations showed a similar pattern (group 1: 0.941, 0.512 and 0.576; group 2: $-0.988,-0.810$ and -0.978 for Holstein cattle, but for Jersey cattle they were relatively lower in some cases: group 1: $0.951,0.261$ and 0.260 ; group 2: $-0.710,-0.490$ and -0.810 ). Phenotypic correlations were very low in both breeds, with the exceptions of CI $\times$ DO and NSC $\times$ CR (group 1: 1.00, 0.047 and 0.050 ; group 2: $-0.047,-0.053,-0.880$ for Holstein cattle, whereas for Jersey cattle they were: group 1: 1.00, 
Table 1 - Descriptive statistical analysis for calving interval (CI) days open (DO), number of services per conception (NSC) and conception rate $(\mathrm{CR})$ of Holstein and Jersey cattle in Antioquia, Colombia

\begin{tabular}{|c|c|c|c|c|c|c|c|c|}
\hline & \multicolumn{4}{|c|}{ Holstein } & \multicolumn{4}{|c|}{ Jersey } \\
\hline & CI & $\mathrm{DO}$ & NSC & $\mathrm{CR}$ & $\mathrm{CI}$ & $\mathrm{DO}$ & NSC & $\mathrm{CR}$ \\
\hline Mean & 410.3 & 127.15 & 1.58 & 79.88 & 409.33 & 125.62 & 1.48 & 84.08 \\
\hline Standard deviation & 77.93 & 76.96 & 1.03 & 28.66 & 86.48 & 86.09 & 0.98 & 27.23 \\
\hline Coefficient of variation & 18.99 & 60.53 & 65.07 & 35.88 & 21.13 & 68.53 & 66.00 & 32.38 \\
\hline Minimum & 250 & 21 & 1.0 & 6.7 & 285 & 21 & 1.0 & 9.1 \\
\hline Maximum & 700 & 415 & 7 & 100 & 698 & 413 & 6 & 100 \\
\hline Number of lactations & 10,303 & 10,156 & 12,883 & 12,883 & 723 & 715 & 879 & 879 \\
\hline
\end{tabular}

Table 2 - Variance components and genetic parameters for calving interval (CI) days open (DO), number of services per conception (NSC) and conception rate (CR) in Holstein and Jersey breeds in Antioquia, Colombia

\begin{tabular}{lccccccc}
\hline Breed & Trait & $\mathrm{V}_{\mathrm{a}}$ & $\mathrm{V}_{\mathrm{pe}}$ & $\mathrm{V}_{\mathrm{e}}$ & $\mathrm{V}_{\mathrm{p}}$ & $\mathrm{h}^{2}(\mathrm{SE})$ & $\mathrm{R}(\mathrm{SE})$ \\
\hline Holstein & $\mathrm{CI}$ & 516 & 29 & 5.305 & 5.850 & $0.088(0.037)$ & $0.093(0.037)$ \\
& $\mathrm{DO}$ & 469 & 105 & 5.126 & 5.700 & $0.082(0.037)$ & $0.101(0.037)$ \\
& $\mathrm{NSC}$ & 0.038 & 0.028 & 0.881 & 0.947 & $0.040(0.025)$ & $0.069(0.026)$ \\
Jersey & $\mathrm{CR}$ & 22 & 33 & 665 & 719 & $0.030(0.026)$ & $0.076(0.027)$ \\
& $\mathrm{CI}$ & 547 & 13 & 7.008 & 7.568 & $0.072(0.098)$ & $0.074(0.116)$ \\
& $\mathrm{DO}$ & 678 & 6 & 6.836 & 7.519 & $0.090(0.104)$ & $0.091(0.123)$ \\
& $\mathrm{NSC}$ & 0.087 & 0.001 & 0.848 & 0.936 & $0.093(0.097)$ & $0.094(0.105)$ \\
& $\mathrm{CR}$ & 104 & 0.074 & 602 & 706 & $0.147(0.117)$ & $0.147(0.121)$ \\
\hline
\end{tabular}

$\mathrm{V}_{\mathrm{a}}$ - additive genetic variance; $\mathrm{V}_{\mathrm{pe}}$ - permanent environmental variance; $\mathrm{V}_{\mathrm{e}}$ - residual variance; $\mathrm{V}_{\mathrm{p}}$ - phenotypic variance; $\mathrm{h}^{2}$ - heritability; $\mathrm{R}$ - repeatability; $\mathrm{SE}$ - standard error.

Table 3 - Variance and covariance components for calving interval (CI) days open (DO), number of services per conception (NSC) and conception rate (CR) in Holstein and Jersey breeds in Antioquia, Colombia

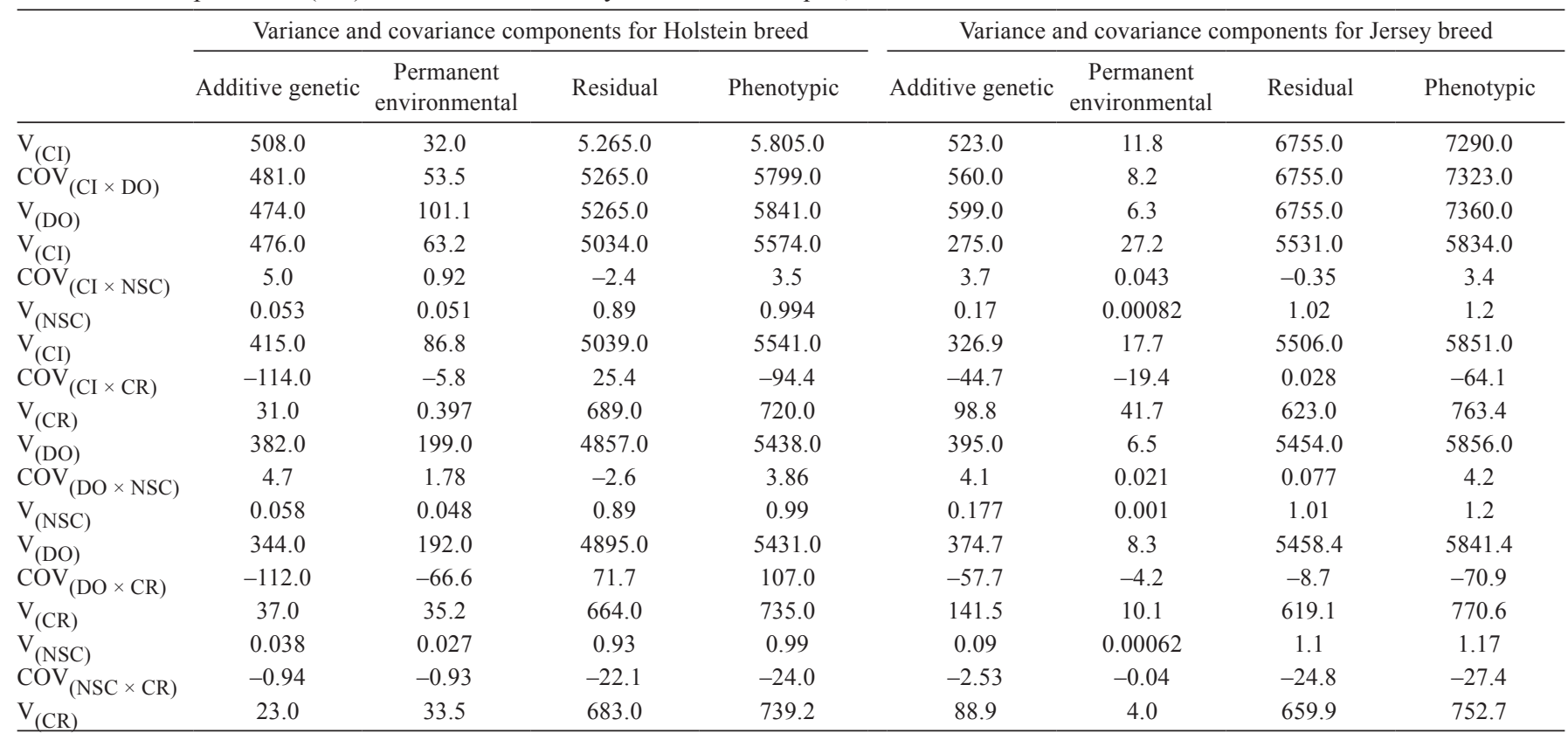

$\mathrm{V}_{(\mathrm{CI})}$ - variance components for calving interval (CI); $\mathrm{V}_{(\mathrm{DO})}$ - variance components for days open (DO); $\mathrm{V}_{(\mathrm{CR})}$ - variance components for conceptions rate $(\mathrm{CR})$; $\mathrm{V}_{(\mathrm{NSC})}$ - variance

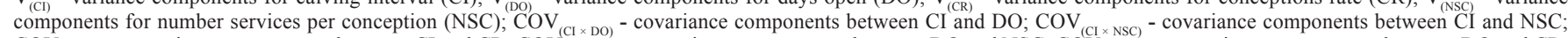

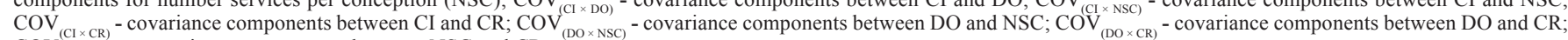
$\mathrm{COV}_{(\mathrm{NSC} \times \mathrm{CR})}^{(\mathrm{Cl} \times \mathrm{CR})}$ - covariance components between NSC and CR.

0.041 and 0.050 , and group 2: $-0.030,-0.033$ and -0.92 ).

Finally, residual correlations were very low in both breeds, with the exceptions of $\mathrm{CI} \times \mathrm{DO}$ and $\mathrm{NSC} \times \mathrm{CR}$ (group 1: $1.00,-0.036$ and -0.039 ; group 2: $0.014,0.040$ and -0.877 for Holstein cattle; and for Jersey cattle, group 1: 1.00, -0.005 and 0.001; group 2: 0.001, -0.005 and -0.930 ).

\section{Discussion}

The results obtained for the mean of each trait are consistent with the results of previous studies, although some authors have reported different values. The mean values for CI obtained in this study for Holstein and Jersey 
Table 4 - Genetic, permanent environmental, phenotypic, and residual correlations for $\mathrm{CI} \times \mathrm{DO}, \mathrm{CI} \times \mathrm{NSC}, \mathrm{CI} \times \mathrm{CR}, \mathrm{DO} \times \mathrm{NSC}, \mathrm{DO} \times \mathrm{CR}$ and NSC $\times$ CR in Holstein and Jersey cattle in Antioquia, Colombia

\begin{tabular}{|c|c|c|c|c|c|}
\hline \multirow{2}{*}{ Breed } & & \multicolumn{4}{|c|}{ Correlations } \\
\hline & & $r_{g}(\mathrm{SE})$ & $r_{p e}(S E)$ & $\mathrm{r}_{\mathrm{e}}(\mathrm{SE})$ & $r_{p}(S E)$ \\
\hline \multirow[t]{6}{*}{ Holstein } & $\mathrm{CI} \times \mathrm{DO}$ & $0.980(0.243)$ & $0.941(1.096)$ & $1.00(0.005)$ & $1.00(0.001)$ \\
\hline & $\mathrm{CI} \times \mathrm{NSC}$ & $0.955(0.450)$ & $0.512(1.325)$ & $-0.036(0.015)$ & $0.047(0.011)$ \\
\hline & $\mathrm{CI} \times \mathrm{CR}$ & $-1.00(0.529)$ & $-0.988(0.010)$ & $0.014(0.015)$ & $-0.047(0.011)$ \\
\hline & $\mathrm{DO} \times \mathrm{NSC}$ & $0.988(0.449)$ & $0.576(0.656)$ & $-0.039(0.015)$ & $0.050(0.011)$ \\
\hline & $\mathrm{DO} \times \mathrm{CR}$ & $-0.993(0.532)$ & $-0.810(0.719)$ & $0.040(0.015)$ & $-0.053(0.011)$ \\
\hline & $\mathrm{NSC} \times \mathrm{CR}$ & $-1.00(0.123)$ & $-0.978(0.139)$ & $-0.877(0.003)$ & $-0.88(0.002)$ \\
\hline \multirow{4}{*}{ Jersey } & $\mathrm{CI} \times \mathrm{CR}$ & $-0.250(1.300)$ & $-0.710(0.569)$ & $0.001(0.076)$ & $-0.030(0.044)$ \\
\hline & $\mathrm{DO} \times \mathrm{NSC}$ & $0.490(1.109)$ & $0.260(1.120)$ & $0.001(0.078)$ & $0.050(0.044)$ \\
\hline & $\mathrm{DO} \times \mathrm{CR}$ & $-0.250(1.031)$ & $-0.490(0.905)$ & $-0.005(0.078)$ & $-0.033(0.044)$ \\
\hline & $\mathrm{NSC} \times \mathrm{CR}$ & $-0.890(0.220)$ & $-0.810(0.407)$ & $-0.930(0.011)$ & $-0.920(0.005)$ \\
\hline
\end{tabular}

CI - calving interval; DO - days open; NSC - number of services per conception; CR - conception rate; $r_{g}$ - genetic correlations; $r_{p e}$ - permanent environmental correlations; $\mathrm{r}_{\mathrm{e}}$ - residual correlations; $\mathrm{r}_{\mathrm{p}}$ - phenotypic correlations, $\mathrm{SE}$ - standard error.

cattle were 410.32 and 409.33 days, respectively, similar to those reported by Sun et al. (2010), Biffani et al. (2005) and González-Recio and Alenda (2005), which were 413.1, 413.5 and 400, respectively. In contrast, Estrada-León et al. (2008), Ajili et al. (2007) and Sven et al. (2005) reported higher means (453.9, 127.01 and 462.6, respectively) and, in constrast, Ghiasi et al. (2011), Wall et al. (2003) and HaileMariam et al. (2003), reported lower means (393.85, 387.94, and 372 , respectively).

Our results for DO were 127.15 and 125.62 days for Holstein and Jersey cattle, respectively. These results corroborate the findings by Sun et al. (2010); Abe et al. (2009) and Sven et al. (2005), who reported 133.29, 126.2 and 129.5, respectively. However, Ríos-Ultrera et al. (2010a), Gredler et al. (2007), González-Recio and Alenda (2005) and Haile-Mariam et al. (2003) reported lower results (102, 105.6, 117 and 93, respectively), and Ajili et al. (2007) and Estrada-León et al. (2008) reported higher results for Brown Swiss cattle (163.34 and 172.8).

In relation to NSC, the results obtained (1.58 and 1.48) for Holstein and Jersey cattle were similar to those reported by Kadarmideen et al. (2000) and Jamrozik et al. (2005): 1.56 and 1.64, respectively. However, Ríos-Ultrera et al. (2010a) and Sven et al. (2005) reported higher results (2.18 and 2.81, respectively).

Regarding CR, the results obtained in this study for Holstein and for Jersey cattle were 79.88 and $84.08 \%$, respectively. Abe et al. (2009) reported lower results: 51.3\% in first-calving and $50.1 \%$ in second-calving cows.

In all the evaluated reproductive traits, different results were observed among the mentioned authors, considering that these traits depend largely on feeding, health and reproductive management, which vary from herd to herd. The conception rate (CR) was particularly high in our study, because many of the unsuccessful inseminations were not recorded.
The heritability obtained for CI in Holstein and Jersey cattle $(0.088$ and 0.072 , respectively) were similar to those reported by Ghiasi et al. (2011), Restrepo et al. (2008) and Demeke et al. (2004) (Table 5). However, these results were lower than those obtained by Ríos-Ultrera et al. (2010a) and Estrada-León et al. (2008), and higher than the results reported by Ríos-Ultrera et al. (2010b) and Sven et al. (2005). As for DO, the heritability estimates obtained in this study were 0.082 and 0.090 for Holstein and Jersey cattle, respectively; this is consistent with the results reported by Pantelic et al. (2011) and Ghiasi et al. (2011). In contrast, some authors report very low heritability values (Estrada-León et al., 2008; M’hamdi et al., 2010; Ríos-Ultrera et al., 2010a).

The heritability estimate for NSC for Jersey cattle (0.090) was very similar to that reported by Demeke et al. (2004), but for Holstein cattle, the heritability in this study was very low (0.040), as were those reported by Ghiasi et al. (2011), Estrada-León et al. (2008) and Veerkamp et al. (2001).

The heritability for CR obtained in this study for Holstein cattle was 0.030, which is in line with the findings of Abe et al. (2009), Tsuruta et al. (2009) and Haile-Mariam et al. (2003), and 0.147 for Jersey cattle; in spite of being low values, they are higher than the results reported by the authors listed above. All these results indicate that reproductive traits are lowly heritable, below 0.10 according to most authors, which implies that they are notably affected by the environment and that the selection of superior individuals would be very slow.

The repeatability estimates for $\mathrm{CI}$ in Holstein and Jersey cattle were 0.093 and 0.074 , respectively. These values were higher than those reported by Ojango and Pollott (2001) and Kadarmideen et al. (2000). Nevertheless, some authors (Estrada-León et al., 2008; M'hamdi et al., 2010; Ríos-Ultrera et al., 2010a) report higher repeatability values (0.120-0.180). Regarding DO, the repeatability values obtained in both breeds 
(0.101, 0.091), are lower than, yet close to those reported by M'hamdi et al. (2010), Estrada-León et al. (2008) and Demeke et al. (2004), which were in a very close range (0.135-0.190). For NSC, the repeatability estimates were 0.069 and 0.094 , similar to those reported by Estrada-León et al. (2008) and Demeke et al. (2004), but higher than those reported by M'hamdi et al. (2010), Biffani et al. (2005) and Kadarmideen et al. (2000), which were in a range between 0.022 and 0.037 . Finally, for CR, the repeatability values found for each breed $(0.076,0.174)$ were higher than those reported by Ríos-Ultrera et al. (2010b), which were 0.03 in Brown Swiss cattle.

The correlations between CI and DO in this study for Holstein and Jersey cattle were 0.98 and 1.00, respectively. These values are similar to those reported by GonzálezRecio and Alenda (2005), Gredler et al. (2007), and Ghiasi et al. (2011), who reported a nearly perfect genetic correlation $(0.99,0.98$, and 0.99 , respectively). These results suggest that these two reproductive traits are genetically equivalent, i.e., they are influenced by the same genes. This is known as pleiotropic effect (Falconer and Mackay, 2001).

The joint analysis of CI and NSC indicates that the genetic association between these two traits is positive and high, according to the results obtained for Holstein cattle (0.955), consistent with those reported by Ríos-Ultrera et al. (2010c) and González-Recio and Alenda (2005) (0.97 and 0.89 , respectively). For Jersey cattle, a genetic correlation between CI and NSC of 0.541 was estimated, corroborating the values obtained by Biffani et al. (2005), Ghiasi et al. (2011) and Wall et al. (2003) for Holstein cattle (0.61, 0.69 and 0.61 , respectively). However, lower values were reported by Kadarmideen et al. (2000) for Holstein cattle (0.22) and by Gredler et al. (2007) for Simmental cattle (0.41).

Likewise, the genetic correlation between DO and NSC was high and favorable for Holstein cattle (0.988), and medium and favorable (0.490) for Jersey cattle. Equivalent results were reported by González-Recio and Alenda (2005) and Ghiasi et al. (2011): 0.94 and 0.72, respectively. Gredler et al. (2007) reported a medium genetic correlation (0.42), equivalent to the correlation found in this study for Jersey cattle. These results suggest the notorious presence of pleiotropic effects between these traits.

The genetic correlation between CI and CR was -1.00 for Holstein cattle. Considering that the pregnancy rate is closely related to the conception rate, the result obtained in this study is similar to that obtained by González-Recio and Alenda (2005) and Ghiasi et al. (2011), who both reported a correlation of -0.99 between $\mathrm{CI}$ and pregnancy rate. For Jersey cattle, the genetic correlation between CI and CR that we obtained was medium $(-0.447)$, similar to the findings obtained by Haile-Mariam et al. (2003), who reported a correlation of -0.57 between $\mathrm{CI}$ and pregnancy rate.

Similarly, the genetic correlation obtained in this study between DO and CR was high and negative for Holstein cattle $(-0.993)$; this is consistent with the results reported by González-Recio and Alenda (2005), Ghiasi et al. (2011) and Abe et al. (2009) $(-0.99,-0.99$ and -0.76 , respectively). For Jersey cattle, in contrast, we obtained a moderately low genetic correlation $(-0.244)$.

Table 5 - Genetic parameters reported by several authors for calving interval (CI), days open (DO), number of services per conception (NSC) and conception rate (CR)

\begin{tabular}{|c|c|c|c|c|c|c|c|c|c|}
\hline \multirow{2}{*}{ Authors } & \multirow{2}{*}{ Breed } & \multicolumn{2}{|c|}{$\mathrm{CI}$} & \multicolumn{2}{|c|}{$\mathrm{DO}$} & \multicolumn{2}{|c|}{ NSC } & \multicolumn{2}{|c|}{$\mathrm{CR}$} \\
\hline & & $\mathrm{h}^{2}$ & $\mathrm{R}$ & $\mathrm{h}^{2}$ & $\mathrm{R}$ & $\mathrm{h}^{2}$ & $\mathrm{R}$ & $\mathrm{h}^{2}$ & $\mathrm{R}$ \\
\hline Ghiasi et al. (2011) & $\mathrm{H}$ & 0.074 & - & 0.076 & - & 0.046 & - & - & - \\
\hline Pantelic et al. (2011) & $\mathrm{H}$ & - & - & 0.105 & - & - & - & - & - \\
\hline M'hamdi et al. (2010) & $\mathrm{H}$ & 0.063 & 0.152 & 0.041 & 0.135 & 0.027 & 0.034 & - & - \\
\hline Ríos-Ultrera et al.(2010a) & $\mathrm{H}$ & 0.130 & 0.130 & 0.010 & 0.160 & 0.030 & - & - & - \\
\hline Ríos-Ultrera et al. (2010b) & BS & 0.030 & 0.120 & 0.000 & 0.140 & - & - & 0.03 & 0.03 \\
\hline Abe et al. (2009) & $\mathrm{H}$ & - & - & 0.074 & - & - & - & 0.049 & - \\
\hline Sun et al. (2010) & $\mathrm{H}$ & 0.067 & - & 0.067 & - & 0.028 & - & - & - \\
\hline Tsuruta et al. (2009) & $\mathrm{H}$ & - & - & - & - & - & - & 0.052 & - \\
\hline Restrepo et al. (2008) & $\mathrm{H}$ & 0.090 & 0.180 & - & - & - & - & - & - \\
\hline Estrada-León et al. (2008) & BS & 0.110 & 0.180 & 0.057 & 0.190 & 0.040 & 0.070 & - & - \\
\hline Gredler et al. (2007) & $\mathrm{S}$ & 0.035 & - & 0.040 & - & 0.022 & - & - & - \\
\hline Biffani et al. (2005) & $\mathrm{H}$ & 0.065 & 0.154 & - & - & 0.027 & 0.037 & - & - \\
\hline Sven et al. (2005) & $\mathrm{H}$ & 0.020 & - & 0.030 & - & 0.010 & - & - & - \\
\hline González-Recio and Alenda. (2005) & $\mathrm{H}$ & 0.040 & - & 0.04 & - & 0.020 & - & - & - \\
\hline Demeke et al. (2004) & $\mathrm{H}$ & 0.080 & 0.140 & 0.040 & 0.140 & 0.070 & 0.080 & - & - \\
\hline Haile-Mariam et al. (2003) & $\mathrm{H}$ & 0.09 & - & 0.040 & - & 0.030 & - & 0.05 & - \\
\hline Wall et al. (2003) & $\mathrm{H}$ & 0.033 & - & - & - & 0.020 & - & - & - \\
\hline Veerkamp et al. (2001) & $\mathrm{H}$ & 0.032 & - & - & - & 0.034 & - & - & - \\
\hline Ojango and Pollott. (2001) & $\mathrm{H}$ & 0.047 & 0.060 & - & - & - & - & - & - \\
\hline Kadarmideen et al. (2000) & $\mathrm{H}$ & 0.022 & 0.049 & - & - & 0.010 & 0.032 & - & - \\
\hline
\end{tabular}

H - Holstein; J - Jersey; BS - Brown Swiss; S - Simmental; $\mathrm{h}^{2}$ - heritability; R - repeatability. 
Likewise, the genetic correlation between NSC and CR obtained in this study was high and negative for both Holstein $(-0.877)$ and Jersey cattle $(-0.972)$, similar to the results reported by González-Recio and Alenda (2005) and Ghiasi et al. (2011) for the genetic correlation between NSC and pregnancy rate $(-0.94$ and -0.73 , respectively). These results suggest that these two traits, CI and CR, are not genetically favored, as could be logically expected.

The phenotypic correlation between CI and DO in this study was perfect and favorable, with values of 1.00 for both breeds. González-Recio and Alenda (2005) and Ghiasi et al. (2011) reported similar estimates ( 0.91 and 0.95 , respectively) for Holstein cattle. In contrast, the phenotypic correlation between CI and NSC was very low both for both Holstein $(0.047)$ and Jersey $(0.041)$ cattle. These results are consistent with those obtained by Ageeb and Hayes (2000) and El Amin et al. (1986) (0.05 and 0.01, respectively). Nevertheless, Ghiasi et al. (2011), González-Recio and Alenda (2005), and Kadarmideen et al. (2000) report higher values $(0.70,0.68$, and 0.69 , respectively). Similarly, the results obtained in this study regarding the phenotypic correlation between DO and NSC are very low (0.050) for both breeds. These results are very similar to those reported by El Amin et al. (1986) (0.01). However, Ríos-Ultrera et al. (2010c) and Ghiasi et al. (2011) report higher phenotypic correlations ( 0.56 and 0.73 ).

The differing results of previous studies may be due to the fact that in our study there was a high number of cows with high days open and calving intervals, and low services per conception because of different factors: failure to record unsuccessful inseminations, low heat detection efficiency, or cows not served due to reproductive problems or, in some cases, to low body condition. Additionally, environmental conditions might have influenced phenotypic correlations: this study, as well as those which obtained low phenotypic correlations between DO and NSC, and between CI and NSC, was carried out in countries with an equatorial climate, unlike most of the studies where higher correlations between these traits were obtained, which were carried out in zones with a subtropical climate.

The phenotypic correlations between NSC and CR obtained in this study were high and negative $(-0.88$ and -0.92 for Holstein and Jersey cattle, respectively), and they were equivalent to the results obtained by González-Recio and Alenda (2005) and Ghiasi et al. (2011) $(-0.75$ and -0.73 , respectively). In contrast, the phenotypic correlations between CI and CR were -0.047 for Holstein and -0.030 for Jersey cattle, unlike the higher values reported by Ghiasi et al. (2011) and González-Recio and Alenda (2005) (-0.95 and -0.91 , respectively). In relation to the phenotypic correlation between DO and CR, the values obtained in this study were -0.053 for Holstein cattle and -0.032 for Jersey cattle, which is consistent with the result reported by Abe et al. (2009) (-0.07), which indicates that the degree of phenotypic association between these two traits is low and negative. The differing results may also be explained by the factors discussed above.

The residual correlations between $\mathrm{CI}$ and DO obtained in the present study were favorable and highly associated, presenting 1.00 in the two breeds studied. These results are similar to the findings of Ríos-Ultrera et al. (2010c), who reported 0.90. Similarly, residual correlations between NSC and CR were negative and highly associated with values of -0.877 and -0.930 in Holstein and Jersey cattle, respectively. Ríos-Ultrera et al. (2010c) and Kadarmideen et al. (2000) reported residual correlation values which were moderately high and negative $(-0.71$ and -0.7829$)$ and corroborate the findings of this study.

As for permanent environmental correlations between CI and NSC, the values obtained were medium and positively associated (0.512 and 0.261 for Holstein and Jersey cattle, respectively). Biffani et al. (2005) and Kadarmideen et al. (2000) reported similar results (0.512 and 0.2502 , respectively) in Holstein cattle. The permanent environmental correlation estimates obtained in this study between CI and CR were also high yet negative in both Holstein and Jersey cattle $(-0.988$ and -0.701 , respectively). Kadarmideen et al. (2000) reported a result of -0.380 , which is medium-low and negative. Regarding the correlation between NSC and CR, the values were -0.978 and -0.810 in Holstein and Jersey cattle, respectively, which are similar to the -0.990 reported by Kadarmideen et al. (2000).

\section{Conclusions}

This study confirms that reproductive traits present low heritability, $<10 \%$ in most cases, in Holstein and Jersey cattle, suggesting that fertility is affected mostly by the environment. Therefore, good management of the fertility traits must be considered in order to improve reproductive efficiency. The high and negative genetic correlations for $\mathrm{CI} \times \mathrm{CR}, \mathrm{DO} \times \mathrm{CR}$, and $\mathrm{NSC} \times \mathrm{CR}$, and high and positive genetic correlations for $\mathrm{CI} \times \mathrm{NSC}, \mathrm{CI} \times \mathrm{DO}$, and $\mathrm{DO} \times \mathrm{NSC}$ in this study suggest that these reproductive traits are genetically equivalent, i.e., they are influenced by the same genes, which reveals the presence of pleiotropic effects. This obviously favors the selection of these traits, as we can predict what will happen to several of the reproductive traits after performing selection on one of them. In this manner, we can integrate information on different traits to propose more efficient selection strategies. 


\section{References}

Abe, H.; Masuda, Y. and Susuki, M. 2009. Relationship between reproductive traits of heifers and cows and yield traits for Holsteins in Japan. Journal of Dairy Science 92:4055-4062.

Ageeb, A. G. and Hayes, J. F. 2000. Reproductive responses of Holstein Friesian cattle to the climatic conditions of central Sudan. Tropical Animal Health and Production 32:233-234.

Ajili, N.; Rekik, B.; Ben Gara, A. and Bouraoui, R. 2007. Relationships among milk production, reproductive traits, and herd life for Tunisian Holstein-Friesian cows. African Journal of Agricultural Research 2:47-51.

Biffani, S.; Canavesi, R. and Samore, A. B. 2005. Estimates of genetic parameters for fertility traits of Italian Holstein Friesian cattle. Stocarstvo 59:145-153.

Boldman, K. G.; Kriese, L. A.; Van Vleck, L. D.; Van Tassell, C. P. and Kachman, S. D. 1995. A manual for use of MTDFREML. A Set of programs to obtain estimates of variances and covariances [DRAFT]. USDA-ARS, Lincoln, NE, USA.

Demeke, S.; Neser, F. W. C. and Schoeman, S. J. 2004. Estimates of genetic parameters for Boran, Friesian and crosses of Friesian and Jersey with the Boran cattle in the tropical highlands of Ethiopia: reproduction traits. Journal of Animal Breeding and Genetics 121:57-65.

El Amin, F. M.; Simerl, N. A. and Wilcox, C. J. 1986. Genetic and Enviromental effects upon reproductive performance of Holstein crossbreds in the Sudan. Journal of Dairy Science 69:1093-1097.

Estrada-León, R. J.; Magana, J. G. and Segura-Correa, J. C. 2008. Genetic parameters for reproductive traits of Brown Swiss cows in the tropics of Mexico. Journal of Animal and Veterinary Advances 7:124-129.

Falconer, D. S. and Mackay, T. F. 2001. Introducción a la genética cuantitativa. 4.ed. Editorial Acribia, Zaragoza, España.

García, G. A.; Cárdenas, C. A.; Monterrosa, V.; Valencia L. and Maldonado, J. G. 2002. Caracterización productiva y reproductiva de las explotaciones ganaderas del bajo Cauca y el litoral Atlántico antioqueños. Haciendas la Leyenda y la Candelaria. Revista Colombiana de Ciencias Pecuarias 15:293-301.

Ghiasi, H.; Pakdel, A.; Nejati-Javaremi, A.; Meharabani-Yeganeh, H.; Honarvar, M., González-Recio, O.; Carabaño, M. J. and Alenda, R. 2011. Genetic variance components for female fertility in Iranian Holstein cows. Livestock Science 139:277-280.

González-Recio, O. and Alenda, R. 2005. Genetic parameters for female fertility traits and a fertility index in Spanish dairy cattle. Journal of Dairy Science 88:3282-3289.

Grajales, H.; Hernández, A. and Prieto, E. 2006. Edad y peso a la pubertad y su relación con la eficiencia reproductiva de grupos raciales bovinos en el trópico colombiano. Livestock Research for Rural Development 18(10). Available at: <http://www.lrrd.org/ lrrd18/10/graj18139.htm> Accessed on: Oct. 23, 2012.

Gredler, B.; Fürst, C. and Sölkner, J. 2007. Analysis of new fertility traits for the joint genetic evaluation in Austria and Germany. Interbull Bulletin 37:152-155.

Haile-Mariam, M.; Morton, J. M. and Goddard, M. E. 2003. Estimates of genetic parameters for fertility traits of Australian HolsteinFriesian cattle. Animal Science 76:35-42.

Henderson, C. 1984. Applications of linear models in animal breeding. 3rd ed. University of Guelph, Canada.

Jamrozik, J.; Fatehi, J. and Kistemaker, G. J. 2005. Estimates of genetic parameters for Canadian Holstein female reproduction traits. Journal of Dairy Science 88:2199-2208.
Kadarmideen, H. N.; Thompson, R. and Simm, G. 2000. Linear and threshold model genetic parameters for disease, fertility and milk production in dairy cattle. Animal Science 71:411-419.

Melendez, P. and Pinedo, P. 2007. The association between reproductive performance and milk yield in Chilean Holstein cattle. Journal of Dairy Science 90:184-192.

M'hamdi, N.; Aloulou, R.; Brar, S. K.; Bouallegue, M. and Ben Hamouda, M. 2010. Phenotypic and genetic parameters of reproductive traits in Tunisian Holstein cows. Biotechnology in Animal Husbandry 26:297-307.

Miglior, F.; Muir, B. L. and Van Doormaal, B. J. 2005. Selection indices in Holstein cattle of various countries. Journal of Dairy Science 88:1255-1263.

Mrode, R. 1996. Linear models for the prediction of animal breeding values. 1st ed. CAB International, Wallingford, UK.

Ojango, J. M. and Pollott, G. E. 2001. Genetics of milk yield and fertility traits in Holstein Friesian cattle on large scale Kenyan farms. Journal of Animal Science 79:1742-1750.

Pantelic, V.; Sretenović, L. and Ostojić-Andrić, D. 2011. Heritability and genetic correlation of production and reproduction traits of Simmental cows. African Journal of Biotechnology 10:7117-7121.

Pryce, J. E.; Royal, M. D. and Garnsworthy, P. C. 2004. Fertility in highproducing dairy cow. Livestock Production Science 86:125-135.

Restrepo, G.; Pizarro, E. and Quijano, J. H. 2008. Índices de selección y niveles independientes de descarte para dos características productivas y reproductivas en un hato Holstein (Bos taurus). Revista Colombiana de Ciencias Pecuarias 21:239-250.

Ríos-Ultrera, A.; Calderón-Robles, R.; Rosete-Fernández, J. and Lagunes-Lagunes, J. 2010a. Análisis genético de características reproductivas de vacas Holstein criadas en un ambiente subtropical. Agronomía Mesoamericana 21:245-253.

Ríos-Ultrera, A.; Calderón, C. R.; Rosete, J. V. and Lagunes, J. 2010 b. Estimación de parámetros genéticos para características de fertilidad en ganado Suizo Pardo bajo condiciones subtropicales en México. Veterinaria México 41:117-129.

Ríos-Ultrera, A. R.; Calderón-Robles, R. C.; Rosete-Fernández, J. V. and Lagunes-Lagunes, J. 2010c. Correlaciones genéticas y fenotípicas entre características reproductivas de vacas lecheras. Agronomía Mesoamericana 21:235-244.

Sun, C.; Madsen, P.; Lund, M. S.; Zhang, Y.; Nielsen, U. S. and Su, G. 2010. Improvement in genetic evaluation of female fertility in dairy cattle using multiple-trait models including dairy yield traits. Journal of Animal Science 88:871-878.

Sven, K.; Nattaphon, C. and Hans-Jürgen, L. 2005. Estimation of variance components for production and fertility traits in Northern Thai dairy cattle to define optimal breeding strategies. Archiv Tierzucht 48:233-246.

Thaller, G. 1997. Genetics and breeding for fertility. Interbull Bulletin 18:55-61.

Tsuruta, S.; Misztal, I.; Huang, C. and Lawlor, T. J. 2009. Bivariate analysis of conception rates and test-day milk yields in Holsteins using a threshold-linear model with random regressions. Journal of Dairy Science 92:2922-2930.

Veerkamp, R. F.; Koenen, E. P. and De Jong, G. 2001. Genetic correlations among body condition score, yield, and fertility in first-parity cows estimated by random regression models. Journal of Dairy Science 84:2327-2335.

Wall, E. S.; Brotherstone, S.; Woolliams, J. A.; Banos, G. and Coffey, M. P. 2003. Genetic evaluation of fertility using direct and correlated traits. Journal of Dairy Science 86:4093-4102. 